\title{
CAROTID CAVERNOUS FISTULA: A RARE CASE REPORT
}

\author{
B. S. Satish Prasad ${ }^{1}$
}

\section{HOW TO CITE THIS ARTICLE:}

B. S. Satish Prasad. "Carotid Cavernous Fistula: A Rare Case Report". Journal of Evolution of Medical and Dental Sciences 2015; Vol. 4, Issue 04, January 12; Page: 721-723, DOI: 10.14260/jemds/2015/104

ABSTRACT: Carotico-cavernous fistula represent abnormal communication between the carotid circulation and the cavernous sinus. They can be classified as direct or indirect which are separate conditions with different aetiologies. Direct Carotico-cavernous fistulas (CCFs) are often secondary to trauma, and as such the demographics reflect the distribution of head trauma, most commonly seen in the young male patients. Presentation is acute and symptoms develop rapidly. In contrast, indirect CCFs have a predilection for the postmenopausal female patient and the onset of symptoms is often insiduous. Other conditions that predispose to increased risk include. Ehlers-Danlos syndrome. Fibromuscular dysplasia.

INTRODUCTION: Carotid cavernous fistula may arise from head injury or may occur spontaneously. Post traumatic cases account for about $75 \%$ of direct fistulas between internal carotid artery and cavernous sinus. These are often associated with fracture of base of the skull.

CASE REPORT: A 32yrs old woman presented with history of head injury followed by right sided ptosis with mild enophthalmos and chemosis. There was no previous history of ocular or systemic disease.

CT angiography revealed enlarged cavernous sinus with several dilated venous channels including ipsilateral superior ophthalmic vein (SOV) in the right orbit.

- Fracture of skull base on right side.

- Mildly dilated enhancing vessels in the right parabasillar and retrobulbar region.

- Slightly prominent cavernous sinus on right side.

- Engorged superior ophthalmic veins on the right side.

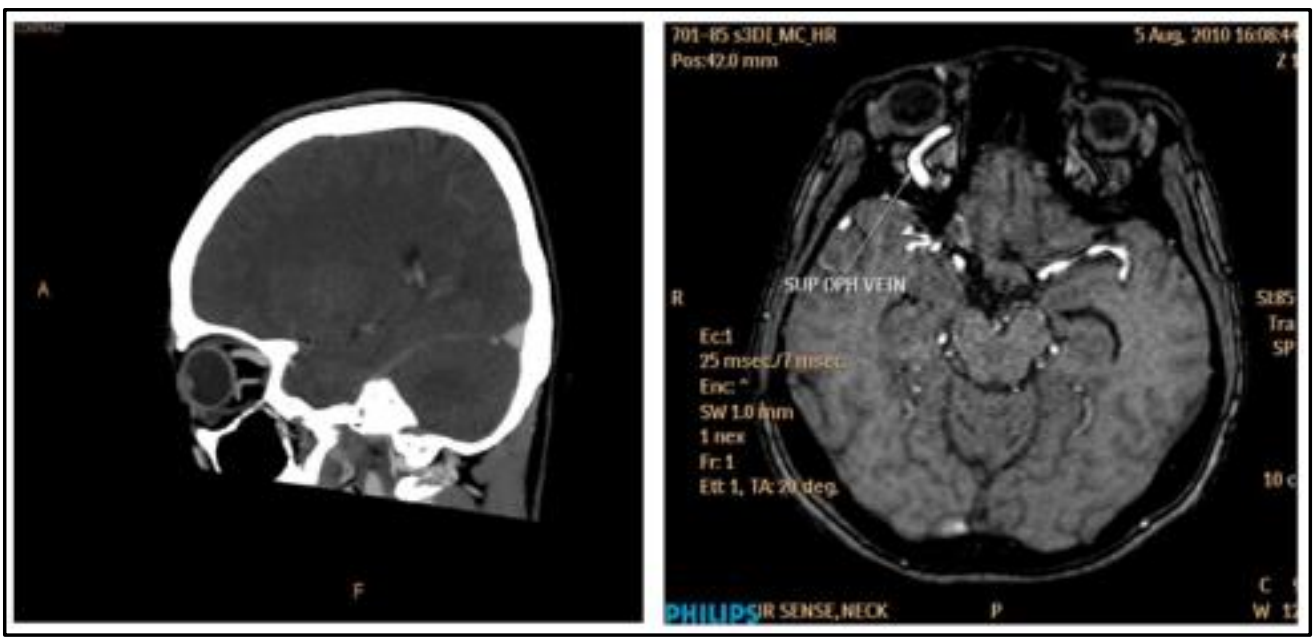




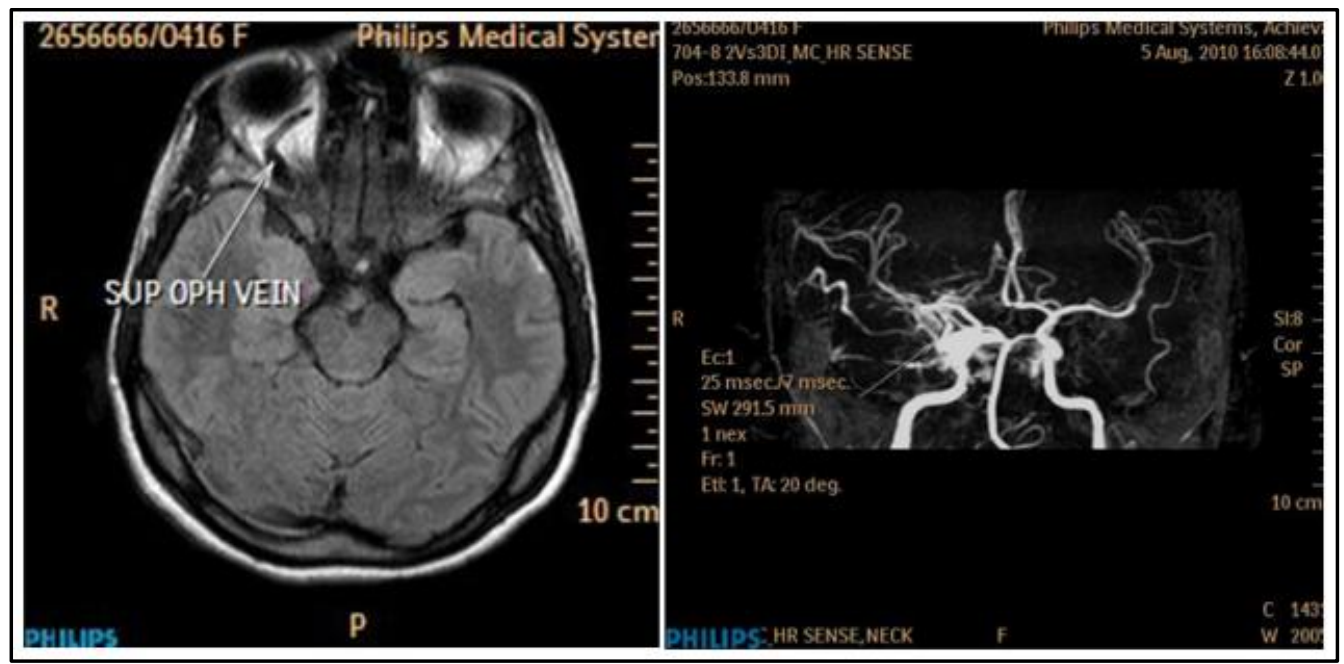

CT and MR angiography reveals enlarged right cavernous sinuses with several dilated venous channels including ipsilateral superior ophthalmic vein in the right orbit.

DISCUSSION: Carotid cavernous fistula results from abnormal communication between arterial and venous systems within the cavernous sinus in the skull base. An arterial blood under high pressure enters the cavernous sinus, the normal venous return to the cavernous sinus is impeded and this causes engorgement of the draining veins, manifesting most dramatically as a sudden engorgement and redness of the eye of the same side

Causes-Carotid cavernous fistula may form from head trauma, surgical damage, rupture of intercavernous aneurysm.

CONCLUSION: Though carotid cavernous fistula is a rare complication of head injury it should be kept in mind in all post traumatic proptosis cases. Early diagnosis and prompt intervention should be made which will not only save the eye but also the life of the patient which is always at risk due to intracerebral bleed secondary to rupture of dilated cavernous sinus.

\section{REFERENCES:}

1. Elster AD. Chen MY, Richardson DN, Yeatts PR. Dilated intercavernous sinuses: anmr sign of carotid cavernous and carotid-dural fistulas.AJNRAm J Neuroradiol, Jul-aug:1991;12 (4): 641-5

2. Halbach VV, Hieshima GB, Higashida RT et-al. Carotid cavernous fistulae: indications for urgent treatment. AJR Am J Roentgenol. 1987; 149 (3): 587-93. AJR Am J Roentgenol.

3. Miller NR. Diagnosis and management of dural carotid-cavernous sinus fistulas. Neurosurg Focus. 2007; 23: E13.

4. Stanton DC, Kempers KG, Hendler BH, Cutilli BJ, Hurst RW. Posttraumatic carotid-cavernous sinus fistula. J Craniomaxillofac Trauma. 1999; 5: 39-44. 


\section{CASE REPORT}

\section{AUTHORS:}

1. B. S. Satish Prasad

\section{PARTICULARS OF CONTRIBUTORS:}

1. Professor \& HOD, Department of Radiodiagnosis, Adichunchanagiri Institute of Medical Sciences.

\section{NAME ADDRESS EMAIL ID OF THE}

\section{CORRESPONDING AUTHOR:}

B. S. Satish Prasad, \# 214/Y, $3^{\text {rd }}$ Block, $53^{\text {rd }}$ Cross, $13^{\text {th }}$ Main,

Rajaji Nagar, Bangalore-560010.

E-mail: satishprasad.bs@gmail.com

Date of Submission: 12/12/2014. Date of Peer Review: 13/12/2014. Date of Acceptance: 02/01/2015. Date of Publishing: 12/01/2015. 